\title{
POLÍTICA EXTERIOR DE COLOMBIA FRENTE A LA DELIMITACIÓN DE FRONTERAS MARINAS Y SUBMARINAS EN EL GOLFO DE COQUIVACOA ${ }^{1}$
}

Colombia's Foreign Policy against the Delimitation of Marine and Submarine Borders in the Gulf of Coquivacoa'

\section{Milton José Pereira Blanco}

Fecha de Recepción: Noviembre 4 de 2013

Fecha de Aceptación: Noviembre 11 de2013

Sumario: 1. Introducción; 2. Las negociones en el diferendo colombo-venezolana en la delimitación de

fronteras en el Golfo de Coquivacoa; 3. Planteamientos, posiciones y bases jurídicas de Colombia y Venezuela en el diferendo Colombo-Venezolano; 4. Dominio territorial en el Golfo de Coquivacoa; 5 Política Exterior Colombiana frente al diferendo Colombo-Venezolano; 6. Conclusión; 7. Referencias bibliográficas.

\footnotetext{
${ }^{1}$ El presente trabajo constituye un informe final de la investigación titulada "Política exterior de Colombia frente a la delimitación de fronteras marinas y submarinas". Este trabajo fue dirigido por el Profesor Oscar Ariza Orozco y se encuentra adscrito a la línea de investigación denominada Política Internacional y Conflictos Internacionales del Grupo de Investigación en Derecho SILA.

${ }^{2}$ Profesor Fundación Universitaria Colombo Internacional, candidato a Magíster en Derecho Universidad del Norte, Especialista en Derecho Contencioso Administrativo de la Universidad Externado de Colombia. Correo electrónico: miltonjosepereirablanco@gmail.com
} 


\title{
COMO SE CITA ESTE ARTÍCULO (APA 6)
}

Pereira Blanco, M. J. (2014) Política exterior de Colombia frente a la delimitación de fronteras marinas y submarinas en el Golfo de Coquivacoa. (Y. Carrillo De la rosa, Ed.) Revista Jurídica Mario Alario D'Filippo, VI (11), pág. 61-79

\section{RESUMEN}

En este trabajo se sostiene, como tesis central, que en asuntos de alta trascendencia nacional e internacional como el diferendo colombo-venezolano, es necesario que el Estado Colombiano fije una política exterior clara y definida, conforme a la política internacional de los órganos y organismos internacionales que velan por el mantenimiento del orden público internacional. Esta política exterior debe estar conforme a las disposiciones de la Constitución Nacional, que al respecto plantea que las relaciones exteriores del Estado se fundamentan en la soberanía nacional, en el respeto a la autodeterminación de los pueblos y en el reconocimiento de los principios del derecho internacional aceptados por Colombia; igualmente, debe orientarse hacia la integración latinoamericana y del Caribe, la cual no se vislumbra en la política exterior colombiana de los períodos analizados.

Esta tesis surge del siguiente interrogante: ¿Cómo se desarrolló la política exterior de Colombia frente a la delimitación de fronteras marinas y submarinas en el Golfo de Coquivacoa?, y en su tenor sostiene que las negociaciones Colombo-Venezolanas en torno al diferendo limítrofe deben redireccionarse, y que la política exterior colombiana debe ajustarse a la actualidad, respetando no sólo los convenios pactados entre ambos estados, sino también los tratados multilaterales y los principios del Derecho Internacional. (Monroy Cabra, 2002)

\section{PALABRAS CLAVE}

Diferendo, fronteras marinas y submarinas, Golfo Coquivacoa, política exterior, política internacional.

\begin{abstract}
ABSTRAC
In this paper argues, as its central thesis, that in matters of high national and international importance as the Venezuelan-Colombian dispute, it is necessary that the Colombian State set a clearly defined foreign policy, under international policy bodies and agencies international who ensure the maintenance of public order international. This foreign policy must be subject to the provisions of the National Constitution, that the matter states that the State's foreign relations are based on national sovereignty, respecting the selfdetermination and recognition of the international law principles accepted by Colombia; also, it should be directed toward Latin American and Caribbean integration, which is not in sight in the Colombian foreign policy of the periods analyzed.
\end{abstract}

This thesis arises by the following question: How Colombia's foreign policy was developed against the delimitation of marine and submarine borders in the Gulf of Coquivacoa?, and in its tenor argues that the Colombo-Venezuelan negotiations on the border dispute should be redirected, and that the Colombian foreign policy must currently fit, respecting not only the conventions concluded between the two states, but also multilateral treaties and principles the International law. (Monroy Cabra, 2002).

\section{KEYWORDS}

Differendum, marine and submarine borders, Gulf Coquivacoa, Foreign policy, International policy. 


\section{INTRODUCCIÓN}

En este artículo se analiza el diferendo Colombo-Venezolano y la delimitación de fronteras marinas y submarinas en el Golfo de Coquivacoa. Este es uno de los territorios más sensibles de América por su impacto Económico, Político, Social e Internacional. Lo anterior a partir del problema jurídico planteado, el cual hace referencia a ¿Cómo se desarrolló la política exterior de Colombia frente a la delimitación de fronteras marinas y submarinas en el Golfo de Coquivacoa?

Es importante empezar por decir que el diferendo en el Golfo de Coquivacoa tiene a los países de Colombia y Venezuela enfrentados, por no definir las fronteras marítimas en dicha área. Este aplazamiento ha derivado en enfrentamientos entre los gobernantes de los dos Estados y genero uno de los momentos de mayor tensión en las relaciones entre los dos países, con efectos en el hemisferio.

Este impase más conocido como la crisis de la corbeta "Caldas" la Corbeta Solitaria, en el Golfo de Coquivacoa se suscitó en 1987. En ese momento se estuvo ad portas de una confrontación armada en el Golfo. Por fortuna fue resuelto por la vía diplomática en el marco del Derecho Internacional, por los representantes de los gobiernos de Bogotá y Caracas: Virgilio Barco de Colombia y Jaime Lusinchi de Venezuela.

Las relaciones entre Colombia y Venezuela han pasado por varias etapas, en las cuales ha sido siempre una constante el diferendo existente entre estos dos países respecto el Golfo de Coquivacoa, constituyéndose el diferendo en uno de los elementos que más incide en las mismas, a la vez que las características de esta frontera marítima y el intercambio comercial se han convertido también con el tiempo, en otro elemento estructural de esta relación bilateral.

La metodología aplicada al presente artículo corresponde al análisis de situaciones, el estudio de los datos, teniendo en cuenta la posibilidad de inferir descriptivamente ideas, al comparar información en los ámbitos de estudio. El objetivo general de este trabajo es determinar el desarrollo de la política exterior de Colombia frente a la delimitación de fronteras marinas y submarinas en el Golfo de Coquivacoa.

Es un trabajo circunscrito al plano eminentemente jurídico, de tipo analítico, documental, de carácter cualitativo, que se desarrollará a nivel dogmático teórico; el cual busca analizar la política exterior de Colombia en la delimitación de fronteras marinas y submarinas en el Golfo de Coquivacoa, y de la literatura existente sobre la materia, determinando los alcances de las posiciones jurídicas de ambos Estados frente al diferendo.

En este marco, el presente trabajo se ha dividido en cuatro apartes, así: El primer aparte denominado: Las negociones en el diferendo Colombo-Venezolano en la delimitación de fronteras en el Golfo de Coquivacoa. El segundo aparte se titula: Planteamientos, posiciones y bases jurídicas de Colombia y Venezuela en el Diferendo Colombo-venezolano. El tercer aparte se aborda el: Dominio territorial en el Golfo de Coquivacoa. El cuarto y último aparte se trabaja el tema: Política Exterior Colombiana frente al diferendo Colombo-Venezolano. Para llegar a las conclusiones 
planteadas es necesario acudir a bibliografía nacional como internacional, incluido documentos oficiales.

\section{LAS NEGOCIONES EN EL DIFERENDO COLOMBO-VENEZOLANA EN LA DELIMITACIÓN DE FRONTERAS EN EL GOLFO DE COQUIVACOA}

En este aparte del presente trabajo, se analiza el proceso de negociación de los gobiernos colombianos y venezolanos frente a la delimitación de fronteras en el Golfo de Coquivacoa. Así las cosas, es de suma importancia en primer término precisar los antecedentes históricos ${ }^{3}$ que tienen incidencia en el diferendo Colombo-Venezolano.

Este proceso se puede dividir en cinco (5) etapas para mayor comprensión así: Una primera etapa denominada del descubrimiento de América. Este período como hecho relevante en cuanto al tema objeto de estudio implica el descubrimiento de las costas de la Nueva Granada desde el cabo Chichibacoa hasta el Golfo de Urabá, por Alonso de Ojeda y Rodrigo de Bastidas.

La segunda etapa, denominada la división de las Capitanías. Este período es importante por cuanto se fijaron límites territoriales; el Virreinato de Nueva Granada o Virreinato de Santa Fe comprendió territorios de las actuales Repúblicas de Colombia, Ecuador, Panamá y Venezuela además de regiones del norte del Perú y Brasil, y el Oeste de Guyana. (Perazzo, 1982)

La tercera etapa, denominada situación jurídica de los Monjes. Es claro que en el desarrollo del diferendo Colombo-venezolano los monjes juegan un papel fundamental, pues son un punto clave en la delimitación de fronteras marinas y submarinas en el Golfo de Coquivacoa. A partir del descubrimiento, este territorio continental e insular se incorpora a los dominios de la Corona y para el efecto de su manejo administrativo comienza aplicarse la teoría de la contigüidad.

Una cuarta etapa denominada de la Gran Colombia y separación de los Estados. Este período es importante por cuanto, una vez lograda la separación definitiva de España, se inició la organización de la República. En un comienzo, nuestro país se unió con Venezuela y Ecuador para formar la Gran Colombia.

Fracasado este intento, nuestro país se estructuró independientemente. Con anterioridad a la Campaña Libertadora de Nueva Granada se había reunido en Santo Tomás de Angostura un Congreso (...) conformado por representantes Venezolanos y Granadinos, Bolívar presidió ese Congreso, el cual aprobó la propuesta del libertador de unir a Venezuela y a la Nueva Granada en una sola República. (Vasquez, 1976,p.10)

La Gran Colombia se disolvió en 1830, como consecuencia de una serie de crisis que demostraron que era imposible mantener la unión de esos territorios en un solo país(Moyano \& Vasquez, 1971).

\footnotetext{
${ }^{3}$ Ver, RALPH ZACKLIN. "El Derecho del Mar en Evolución: La Contribución de los Países Americanos". México: Fondo de Cultura Económica, 1975. (Sección de Obras de Política y Derecho). Además PEARSON, Frederics y ROCHESTER José Martín. "Relaciones Internacionales y Situación Global en el Siglo XXI”. 4 ED. Bogotá: Mc Graw Hill, 2001. ISBN: 0-07-049083-X. MOYANO BONILLA, Cesar y VÁSQUEZ ROCHA, Ernesto. “Los Monjes y las Bahías Históricas ante el Derecho Internacional”. Bogotá: TEMIS. 1971.
} 
Desde este momento la incertidumbre limítrofe en el mal denominado Golfo de Venezuela, entre Colombia y Venezuela, y el surgimiento casi que instantáneo del diferendo Colombo-Venezolano por la dificultad de aplicar el principio del Uti Possidetis luris de 1810 por falta de títulos precisos y de conocimiento de gran extensión de regiones inexploradas.

Una última etapa, para terminar, denominada la crisis de la corbeta Caldas. Este hecho muestra una situación de inestabilidad en cuanto a la situación del diferendo Colombo-Venezolano, a pesar de largos años de negociación directa de los Estados.

En agosto de 1987 dos naves de guerra Colombianas ingresaron en aguas que Venezuela reclama como suyas, lo cual fue seguido por la mayor movilización que las fuerzas armadas Venezolanas hayan realizado. La Crisis de la corbeta Caldas tuvo como causa la disputa de soberanía en el Golfo de Venezuela, sobre el cual no existe una delimitación aceptada por ambos países. No fue un hecho fortuito y sus causas aún no han sido resueltas.

La situación actual que vive Colombia y Venezuela de alguna forma desfavorece las negociaciones bilaterales limítrofes de los dos Estados, por tanto afecta enormemente la salida pacífica de las negociaciones diplomáticas entre Colombia y Venezuela ${ }^{4}$. (Gori, 2006)

Para el estudio del desarrollo histórico de las negociaciones entre Colombia y Venezuela sobre los puntos centrales del diferendo en el Golfo de Coquivacoa es importante precisar que ambos países, aún antes de iniciar la epopeya libertadora, acordaron que el Uti Possidetis luris de 1810 sería el fundamento jurídico del deslinde territorial.(Holguin, 1971) .

En el caso Colombiano correspondió inicialmente a los negociadores definir cuál era la línea en derecho, esto es el límite de las Gobernaciones y Provincias del Virreinato de la Nueva Granada con las de la capitanía general de 1810. Así, fue necesario dividir el estudio histórico en varios sectores territoriales para definir los límites fronterizos de cada Estado. (Cavalier, 1977) ${ }^{6}$. (Nueva Granada y Venezuela)

Es importante referirnos al sector de la Guajira ya que fue uno de los más arduamente discutidos en todo el proceso de negociación de límites entre los dos países, además es el punto central de este trabajo.

En este aparte del presente trabajo, es de suma trascendencia explicar los argumentos sostenidos durante las negociaciones tanto del Estado Colombiano como del Venezolano, así:

\footnotetext{
${ }^{4}$ Tanto Venezuela como Colombia han delimitado Unilateralmente, por lo cual las áreas de patrullaje de sus Armadas se solapan. Como si fuera poco, la Crisis de la Corbeta Caldas no fue la primera ocasión cuando se corrió el Riesgo de una Confrontación Armada en el Golfo de Venezuela. Es la situación más crítica desde 1987 cuando se produjo un Conato de Guerra en el Golfo de Coquivacoa o de Venezuela, se encuentran hoy las Relaciones de Colombia y Venezuela, como consecuencia del fuerte altercado verbal que han sostenido los presidentes Álvaro Uribe Vélez y Hugo Chávez. (Gori, 2006)

${ }^{5}$ En efecto en un Tratado suscrito en 1811 por el presidente de Cundinamarca Jorge Tadeo Lozano y el canónico Cortes De Madariaga, en representación de la Junta de Caracas, se señaló vagamente el principio que más tarde fue definido por la Ley Fundamental de Colombia de 1819 y el Artículo 5 de la Constitución expedida en Cúcuta en 1821.(Holguin, 1971)

${ }^{6}$ Los sectores divisionales entre nueva granada y Venezuela quedaron así; desde los Frailes hasta las Serranías de Montes de Oca, de esta hasta el nacimiento del Río Oro, de allí hasta el Río Táchira, del Táchira al nacimiento del Oira, del Oira hasta el Meta, desde allí hasta los raudales de Atures y Maitures y desde esto a la Piedra del Cocuy. (Cavalier, 1977)
} 
El Estado Venezolano sostuvo que la frontera común debería comenzar en el Cabo de la Vela, desde donde dividiendo la península Guajira en dos partes seguiría por una curva a la Teta Goajira, a los Aceites y a Montes de Oca. (Cavalier, 1977).

El Estado Colombiano por su parte consideraba que el límite debía iniciarse en la desembocadura del Caño Paijama en el Golfo de Venezuela no muy lejos de la ciudad de Maracaibo y continuar por el Río Socuy aguas arribas hasta encontrar las Serranías de Montes de Oca. (Gaviria, 2001)

Sobre este punto, el profesor Luís Carlos Zarate señaló sobre las negociaciones colombovenezolanas "que durante el periodo de 1833 a 1840 se firma el Tratado Pombo-Michelena que fue aprobado por el Congreso de Colombia en 1834 pero en cambio fue negado por el Congreso de Venezuela en 1840, a pesar de la línea ventajosa para Venezuela" (Zarate, Luis, 2000 p. 175). Hacia el período de 1844 durante el Gobierno Constitucional del doctor Fermín Toro tienen lugar las negociaciones Toro-Acosta, que son suspendidas en vista de las nuevas pretensiones de Colombia. (Monroy Cabra, 2002)

Asimismo, el profesor Monroy Cabra sobre el particular expone que surgieron durante el período de 1846 a 1874 reuniones de negociación, dentro de ellas Manuel Ancizar y Juan Manrique en 1846, Medardo Rivas y Ricardo Aranda en 1851, negociaciones entre Manuel Murillo Toro y Fernando Arévalo en 1868 y las negociaciones de Aníbal Galindo y Julián Viso en 1877. (Wills Edurado, 1992)

Durante el gobierno del General Antonio Guzmán Blanco se dieron las negociaciones con Antonio Leocadio denominadas Guzmán-Murillo, Venezuela se opone categóricamente a las aspiraciones de Colombia sobre la Guayana. Se acepta, en principio, bajo ciertas condiciones, que Colombia llegase al Orinoco.

Luego de una serie de tropiezos durante las negociaciones se restablecieron las relaciones entre Venezuela y Colombia; Guzmán Blanco busca un avenimiento y se llega a un acuerdo sobre arbitraje. Designado Alfonso XIII, Rey de España como el árbitro natural, acepta la misión de 1883. Venezuela era contraria al Arbitramento y a ello fue obligada por las circunstancias o sucesos posteriores al año de 1874. (Londoño Julio, 1987)

Posteriormente en 1886 Guzmán Blanco firmó en París el Acta declaratoria por la cual muerto el Rey de España, podía conocer como árbitro en el asunto la Reina viuda María Cristina. La Cláusula en el que se convirtió el Árbitro en Árbitro Arbitrador, fue funesta para los intereses Venezolanos. La Reina María Cristina dictó el Laudo en marzo de 1891, cuya decisión tardó siete años, siendo manifiestamente favorable a Colombia.

No obstante, Venezuela, que pudo haber objetado con ventaja dicho Laudo, puso una vez más su celo escrupuloso en los principios, y su prestigio moral por encima de sus propias conveniencias Nacionales, y decidió reconocerle fuerza obligatoria a un fallo que le era tan desfavorable y se dispuso a darle cumplimiento. De hecho en 1894 a 1896 Colombia ofrece territorios en la Guajira,

'La Cédula Real del 8 de junio de 1501 mediante la cual la Corona de España designó a Alonso De Ojeda como Gobernador de la Provincia de Coquivacoa y, en la Disposición del 27 de marzo de 1528, por la que Carlos V dio en arrendamiento a la compañía mercante de los Welser de la ciudad de Hamburgo, el territorio comprendido entre Marcapana y el Cabo de la Vela. (Gaviria, 2001,p.20) 
Meta y Orinoco, cuando pretendía la cesión de extensas áreas del Catatumbo, Tarra, Sardinata, Grita y Zulia. (Monroy, 2002)

La sentencia del Consejo Federal Suizo en 1922 eliminó toda posibilidad de Cesión Mutua de Territorios. Por su parte el Gobierno del General Ignacio Andrade se llegó a un pacto reglamentario del laudo y a la creación de una Comisión Mixta. Luego de los trabajos de la Comisión Mixta acordados entre Colombia y Venezuela en los años de 1915 a 1916 vino la designación del Árbitro Suizo para la Ejecución Integra del Laudo y se resolvió que el Árbitro debería determinar los límites después de estudio previo. (Pardo Rodrigo, 1988)

Luego se crea una comisión mixta Colombo-Venezolana para demarcar en el terreno los sectores que no estaban determinados, se inician las discusiones del Río de Oro. "En 1941 se firma el tratado sobre demarcación de Fronteras y navegación de los Ríos Comunes entre Venezuela y Colombia. En 1969 en Sochagota se suscribe una declaración conjunta en que se establece la negociación directa como medio de solución pacífica del diferendo, por tanto al año siguiente se suscribe el modus operandis de dicha declaración, que se ejecutaron hasta 1973". (Monroy, 2002, p 672)

Hacia finales de los años 70, precisamente en el año 1979 se realizan negociaciones diplomáticas entre los dos Estados y como resultado se obtuvo un proyecto de tratado internacional bilateral denominado hipótesis de Caraballeda en donde se establecen líneas de delimitación transaccionales con base en el Castillete y en las líneas rectas que ampliaban la jurisdicción Venezolana frente a Paraguay y las Colombiana frente a la Guajira; posteriormente la hipótesis no encontró sustento ni apoyo en Venezuela y se dio por terminada la negociación diplomática. Colombia en múltiples ocasiones ha propuesto la aplicación del tratado de no agresión, conciliación, arbitraje y arreglo judicial, el cual no ha encontrado viabilidad por parte de Venezuela, en el año 1987 con julio paredes y anteriormente con Alfredo Vásquez Carrizosa. Estudios recientes ${ }^{8}$ sobre las negociaciones diplomáticas entre Colombia y Venezuela en la delimitación de sus límites marítimos y submarinos han llegado a establecer certeramente que entre ambos estados siguen las negociaciones de manera reservada, a través de comisiones binacionales ${ }^{9}$.

Para terminar este punto, es de suma importancia señalar que el proceso de negociación entre el Estado Colombiano y el Estado de Venezuela históricamente ha estado marcado por la inestabilidad política de los gobiernos de turno, teniendo en cuenta que durante ciertos períodos, hubo voluntad directa de los países de resolver el diferendo colombo-venezolano y en otras épocas históricas, se propendió por un MASC de carácter internacional amparado en el derecho internacional, caso tribunales de arbitramento, pero sin embargo no se llegó a nada definitivo. Así mismo, en épocas posteriores se retoma la negociación directa pero sin voluntad clara de los Estados implicados en

\footnotetext{
${ }^{8}$ Ver RAMÍREZ, Socorro y CADENAS, José María. “Colombia-Venezuela. Agenda Común para el Siglo XXI”. Bogotá: Tercer Mundo, 1999. además ver. RAMÍREZ, Socorro y RESTREPO, Luís Alberto. "Colombia entre la Inserción y el Aislamiento". Política Exterior Colombiana en los años Noventa. Bogotá: Universidad Nacional, 1997. (Siglo del Hombre). ISBN: 958-6650057. (Instituto de Estudios Políticos y Relaciones Internacionales)

${ }^{9}$ En los gobiernos de César Gaviria Trujillo y Ernesto Samper Pizano. Se ha continuado la negociación diplomática a través de comisiones de los dos estados, pero sin resultados positivos; aunque es preciso tener en cuenta el acta de San Pedro Alejandrino suscrita por los presidentes de Colombia y Venezuela aunque no ha cumplido todos los requerimientos para convertirse en tratado internacional como acto jurídico estatal complejo y porque además no puede resultar dificultoso debido a que no establece plazo para concluir las negociaciones.
} 
resolver el diferendo frente a la delimitación de fronteras marinas y submarinas en el Golfo de Coquivacoa.

\section{PLANTEAMIENTOS, POSICIONES Y BASES JURÍDICAS DE COLOMBIA Y VENEZUELA EN EL DIFERENDO COLOMBO-VENEZOLANO}

En este punto se analizarán las teorías jurídicas expuestas por Venezuela y Colombia para la definición de las fronteras marinas y submarinas en el Golfo de Coquivacoa. Estos planteamientos han sido los siguientes:

a. Tesis de la línea media: Colombia propuso desde el primer momento como línea de derecho en castillete; la "línea media" aprobada en la Convención de Ginebra de 1958, puesta en práctica por Venezuela. Por medio de esta línea se procura dividir en áreas iguales a las aguas de dos estados colindantes o cuyas costas se enfrentan.

b. Tesis es la línea de prolongación de la frontera terrestre: esta Línea propuesta por Venezuela, no obedece a ningún planteamiento técnico, es arbitraria, solo ofrece equidad cuando cae perpendicularmente a la costa. En el caso que estudiamos la casi totalidad del golfo quedaría en manos de nuestros vecinos.

c. Tesis de la Costa Seca: esta hace referencia a una restricción a solo la tierra firme del territorio Colombiano entre Castilletes y la punta más Oriental.

d. Tesis de la Bahía Histórica, planteada por el país Venezolano hace referencia a que el Golfo de Venezuela queda sujeto al Régimen de Aguas Interiores del Estado ribereño. En 1967 la primera reunión formal para acordar el lindero en el Golfo de Coquivacoa se celebró en Bogotá en octubre de 1967, ahora proponía la Línea de Prolongación de la Frontera, además exigió para los Monjes, mar territorial y Plataforma. No se llegó a ninguna aproximación. Desde el mismo comienzo de estas iniciales aproximaciones, la posición vecina ha sido: Prolongación de la Frontera Terrestre Colombiana hacia el Mar.

e. Tesis de la fijación de la línea media: No siendo los islotes de los Monjes sino simples Emergencias de la Guajira será un contrasentido que ellos generaran Plataforma. En cuanto a Mar Territorial, no puede tener la misma amplitud que el que genera la Península de la Guajira, es decir, que en el establecimiento de la Línea Media, sobre las 19 millas que separan a ambos países, no es posible la aplicación del Principio de la Equidistancia".

El Estado Español expidió una serie de reales cédulas que han servido de argumentos para ambos Estados para reclamar su soberanía, es por ello que en Colombia más que en Venezuela se habla de la Teoría del Principio de la Anexión o de la Prolongación de los Monjes (Cavalier, 1977). También conocida además como la Teoría de la Contigüidad, según la cual al Estado continental se le reconocen como suyas aquellas Islas Adyacentes a su territorio y que estén separadas apenas por 
un "brazo de mar"10. Es por ello que a las provincias que componían los Virreinatos y capitanías generales en que se dividieron los territorios de ultramar, se les adjudicó alguna isla o formación insular.

El profesor Luis Carlos Zarate sostiene como hipótesis al problema, entre Colombia y Venezuela, la Plataforma Común; en este sentido plantea lo siguiente:

"Para defenderse esta línea, tal era la tesis de Colombia, los negociadores Colombianos habían tomado como base la Convención de Ginebra sobre Plataforma Continental, aprobada en 1958, en la cual se consagró el Derecho de cada país a la Plataforma Submarina que prolonga sus costas, más allá del Mar Territorial. La convención establece que ese derecho se extiende como norma general hasta una profundidad de $200^{\mathrm{m}}$; o hasta una todavía mayor, si ella permite la explotación de los recursos marinos. En el caso del área que es el motivo de la discusión, la profundidad no alcanza en ningún punto los $200^{\mathrm{m}}$, de modo que la Plataforma que se extiende desde el territorio Colombiano de la Guajira hacia el Oriente, y la que prolonga el Venezolano de Paraguaná hacia el Occidente, están sobrepuestas. (Zarate, Luis, 2000 p. 175)

Los argumentos jurídicos expuestos por el Estado Colombiano, se fundan en las fuentes del derecho internacional, tales como: los tratados internacionales, la jurisprudencia de la Corte Internacional de Justicia y la costumbre internacional; aunque también se vale de principios del Derecho Internacional Americano para sustentar su posición frente al diferendo Colombo-Venezolano. Uno de los argumentos importantes con que cuenta el Estado Colombiano frente a la delimitación de fronteras marinas y submarinas en el Golfo de Coquivacoa es la aplicación al caso en concreto del principio del Uti Possidetis /uris ${ }^{11}$ que la $\mathrm{CIJ}^{12}$ ha interpretado de la siguiente manera;

"Este principio fue invocado por primera vez en América Hispana, no es una norma que pertenezca solamente a un sistema particular del Derecho Internacional, se trata de un Principio de Alcance General, conectado lógicamente al fenómeno de la obtención de la Independencia, donde quiera que ocurra. Su finalidad obvia es impedir que la Independencia y la Estabilidad de los nuevos Estados sean amenazadas por luchas fratricidas provocadas por controversias fronterizas (...,.). El principio de Uti Possidetis luris concede precedencia al Título Jurídico sobre la posesión efectiva como base de la Soberanía. Su principal propósito es Garantizar el Respeto de los Límites Territoriales que existían en el momento en que se logró la Independencia. Cuando esos límites no eran más que delimitaciones entre diferentes divisiones administrativas o colonias, sujetas todas ellas al mismo Soberano, la aplicación de ese principio entregó como resultado su transformación

\footnotetext{
${ }^{10}$ Un fenómeno geológico denominado Tectónico de Placas se presenta en alguna de las zonas del diferendo Colombo-Venezolano el cual ha dado origen a una nueva interpretación del origen geológico del área. Todo parece indicar que la subsidencia de la Cuenca de Maracaibo se ha venido produciendo por la Separación de la Cordillera de los Andes en el llamado Nudo de Pamplona, en territorio Colombiano, en los dos ramales constituidos por el sistema de Perijá al Oeste y los Andes Venezolanos propiamente dichos al Este y esta separación parece haber sido ocasionada por la inserción de una parte de la placa del Caribe, como una cuña y en forma de plano inclinado, en dirección N.E.-S.O.

${ }^{11}$ Otro fallo mediante el cual la CIJ utilizó para resolver una controversia limítrofe internacional fue el «Caso relativo a la controversia sobre fronteras terrestres, insulares y marítimas (El Salvador contra Honduras: Intervención de Nicaragua)», que falló el 11 de septiembre de 1992.

${ }^{12}$ Corte Internacional de Justicia.
} 
en Fronteras Internacionales ${ }^{13}$ [...] La obligación de respetar las Fronteras Internacionales preexistentes deriva de una norma general de Derecho Internacional relativa a la Sucesión de los Estados"(Medina, 2007) ${ }^{14}$.

Otra base jurídica de los argumentos Colombianos en la delimitación las fronteras marinas y submarinas en el Golfo de Coquivacoa es el Principio de Pacta Sunt Servanda que faculta a Colombia a exigir el cumplimiento de los tratados internacionales firmados entre ambos Estados es decir Colombia y Venezuela, pues en algunos casos Venezuela se ha opuesto a resolver el diferendo a través de los diferentes medios pacíficos de controversias, tales como conciliación y el arbitramento consignados en los tratados de 1939 y el tratado de 1941, lo cual tal principio obliga a Venezuela en las circunstancia del caso a su ejecución. Sobre tal principio se ha expresado que:

"Uno de los principios esenciales del Derecho Internacional, pues consagra la norma Pacta Sunt Servanda, según la cual "todo Tratado en vigor obliga a las partes y debe ser cumplido por ellas de buena fe". Este principio de Pacta Sunt Servanda, según el cual los Tratados deben ser cumplidos por las partes que se obligaron, constituye la base esencial del Derecho de los Tratados y, en general, del funcionamiento armónico y pacífico de la Comunidad Internacional. Por ello, algunos teóricos han considerado que esta norma representa el principio base, la norma fundamental y más elemental de todo el sistema jurídico del Derecho Internacional, de la cual depende la validez de las reglas de este derecho. Ahora bien, Pacta Sunt Servanda no solo significa que los Tratados deben ser formalmente acatados sino que deben ser cumplidos de buena fe, esto es, con la voluntad de hacerlos efectivos.

Por ello la Doctrina y la Jurisprudencia Internacional considera que el principio de buena fe es parte integrante de la norma Pacta Sunt Servanda, tal y como lo ha reconocido la Corte Internacional de Justicia ${ }^{15}$ y tal como lo estableció la Carta de las Naciones Unidas, la cual en el numeral $2^{\circ}$ del Artículo $2^{\circ}$ establece que los miembros de la ONU, "a fin de asegurarse los derechos y beneficios inherentes a su condición de tales, cumplirán de buena fe las obligaciones contraídas por ellos de conformidad con esta Carta. Este principio de que Colombia debe cumplir de buena fe sus Obligaciones Internacionales tiene evidente sustento constitucional, pues la Carta señala que las actuaciones de las autoridades colombianas deben ceñirse a los postulados de buena fe (CP Art. 83), norma que se aplica también a las Relaciones Internacionales. Además, la norma de la buena fe en el cumplimiento de las Obligaciones Internacionales por los Estados no solo ha sido tradicionalmente reconocida por Colombia sino que su consagración expresa en la Carta de las Naciones Unidas se debe a la propuesta de los delegados colombianos en la Conferencia de San Francisco ${ }^{16}$. (González, 1998)

Es importante decir, que las bases jurídicas de los argumentos Colombianos, se encuentran conforme al derecho internacional, pues aplica teorías de integración ${ }^{17}$ para mantener la armonía

\footnotetext{
${ }^{13}$ DIEZ DE VELAZCO, Manuel. “Instituciones de Derecho Internacional Público”. T. I. $3^{\circ}$ Ed. Madrid. Editorial Tecno, 1976, pág. 39.

${ }^{14}$ Esta es la esta razón de la Corte Internacional de Justicia en el «Caso relativo a la controversia fronteriza (Burkina Faso contra la República de Mali)», cuyo fallo se dio el 22 de diciembre 1986.

${ }^{15}$ Fallo del 27 de agosto de 1952, I.C.J Reportes, 1952, pág. 212.

${ }^{16}$ Ver YEPES DE UPRIMNY, Inés. YEPES, Jesús María. “EI Derecho Internacional Americano”. Bogotá: Temis, 1980, pág. 167 y 168.

${ }^{17}$ Sobre este punto ver la sentencia C-400/98. Corte Constitucional.
} 
entre su derecho interno y el derecho internacional, aras de salvaguardar la seguridad jurídica dentro del sistema normativo Colombiano. (Monroy, 1995)

Lo que hemos planteado en este trabajo es precisamente la importancia que tiene la relación entre el Derecho Internacional y el Derecho Interno ya que si países en conflicto, litigio o diferendo armonizaran el sistema jurídico, la salida a los problemas de índole internacional se tornará un tanto más sencilla.

\section{DOMINIO TERRITORIAL EN EL GOLFO DE COQUIVACOA ${ }^{18}$}

En este punto, se analiza cómo ha sido el dominio del territorio en el Golfo de Coquivacoa. Sobre este punto, es importante señalar que el dominio material mayoritariamente lo ha ejercido la República Venezolana. Así las cosas, el interés para resolver el diferendo debe ser en este caso del Estado Colombiano.

Es importante empezar por decir que hasta 1868 no se evidencian actos o hechos que demuestren la tenencia del Golfo de Coquivacoa por parte de Colombia, es por ello que esta etapa para este país fue una etapa de meras negociaciones. Así las cosas, se puede afirmar que Colombia no ha ejercido soberanía en el Golfo de Coquivacoa de manera material, puesto que formalmente lo hizo valer en

\footnotetext{
${ }^{18}$ El conflicto fronterizo en el Golfo de Venezuela. El conflicto de la delimitación marítima entre Colombia y Venezuela en el Golfo de Venezuela, se desarrolló desde 1939 como una ampliación de un antiguo conflicto de frontera terrestre que se inició en tiempos coloniales. Este nació debido a la superposición de un límite entre unidades administrativas en el occidente y el oriente con un límite cultural que se extendía en sentido transversal a los primeros lindando con los indígenas "salvajes" de la península de la Guajira, los cuales no pudieron ser conquistados y convertidos en cristianos hasta fines de la época colonial. Después de la independencia de Colombia y Venezuela a principios del siglo XIX, empezaron ambos países con negociaciones sobre una frontera terrestre para dividir la península de la Guajira en dirección longitudinal. Cuando las negociaciones fracasaron reiterativamente por causa de exigencias incompatibles, los interesados solicitaron un fallo de la Corona Española, el cual se hizo público en 1891, pero que no se pudo delimitar en el terreno debido a sus indicaciones geográficas imprecisas. Una larga serie de negociaciones bilaterales, la solicitud de un segundo fallo al Consejo Federal Suizo (1922) y otra ronda de negociaciones llevaron, apenas en 1941, hacia un arreglo fronterizo definitivo, el cual sin embargo ha sido puesto frecuentemente en duda. La expansión de la problemática fronteriza hacia el espacio marítimo se inició por medio de un decreto venezolano de septiembre de 1939, según el cual una línea recta sale desde el pueblo fronterizo de Castilletes sobre la costa oriental de la península de la Guajira en sentido occidente-oriente y separa las «aguas interiores venezolanas» del Golfo de la zona exterior. Colombia reaccionó a finales de los años cuarenta con la solicitud de calcular una línea media según el derecho del mar (la cual se extiende desde Castilletes en dirección suroriente hasta el centro del Golfo y luego continúa hacia el norte) y con reclamos sobre las Islas Monjes. Colombia reconoció la soberanía venezolana sobre estas microislas en 1953, pero no obstante el problema de una línea que marque el límite exterior del Golfo y la fijación del mar territorial, ante todo en la región fronteriza de Castilletes, como también entre las Islas Monjes y la península de la Guajira, continúa en la discusión política. En los años sesenta se agregó un nuevo componente por causa de concesiones para prospección petrolera adjudicadas por Colombia directamente frente a Castilletes. Después de largas negociaciones los presidentes de ambos países acordaron en 1975 delimitación marítima y un uso conjunto de las zonas fronterizas potencialmente ricas en petróleo. En Venezuela este plan provocó un fuerte rechazo, generando en 1980 la tesis de la "Costa Seca», es decir de una restricción a solo la tierra firme del territorio colombiano entre Castilletes y la punta más oriental. En el mismo año la Comisión Fronteriza Bilateral presentó la propuesta conocida como «Hipótesis de Caraballeda» para una delimitación en la región del Golfo. En Venezuela esta propuesta provocó fuertes protestas por parte de los partidos políticos, militares y grupos económicos, sociales, religiosos y científicos. No obstante, todo acercamiento hacia un compromiso fue bloqueado en Venezuela por fuertes reacciones nacionalistas hasta llegar a una intervención militar (golpe militar en febrero de 1992 en relación con la problemática del Golfo). Aquí tienen gran fuerza corrientes nacionalistas con constante referencia a presuntos perjuicios históricos, con palabras como «intereses vitales» o «integridad nacional» que piensan en dimensiones terrestres (soberanía-territorio-frontera) y con el rechazo absoluto de llevar este diferendo ante la Corte Internacional.
} 
su Constitución Nacional, Artículo $101^{19}$, pero aunque los artículos constitucionales son de cumplimiento inmediato, y tal artículo tiene dificultad en cuanto a su aplicación, ya que establecen que los límites del Estado Colombiano son los que establecen los laudos arbítrales, y tal es el caso del laudo de la reina regente María Cristina de España, y dicho laudo no produce efectos directos de ninguna índole. Al señalar que no produjo efectos directos hacemos referencia a que por sí solo el laudo no tuvo fuerza vinculante aunque se le trato de entregar valor jurídico posteriormente a través del laudo federal Suizo y las comisiones Binacionales ${ }^{20}$.

Es importante evidenciar una serie de proyectos y obras ejecutados por el gobierno Venezolano, que muestran claramente el ejercicio pleno de la soberanía Venezolana en ese territorio, más la defensa territorial ejercida a través de sus fuerzas militares, al punto de ocasionar el incidente de la Corbeta Caldas en aras de defender el territorio del Golfo, aunque parte del territorio en disputa este ocupado de facto ya que existe aplicación del Uti Possidetis de Facto y no el Uti Possidetis de luris de que tanto predica Venezuela.(Gaviria, 2001)

A nuestro modo de ver, esto es el ejercicio de una ocupación de facto, ya que el ejercicio de la soberanía no puede ser pleno, debido a la existencia de un diferendo, el cual reporta eventuales derechos colombianos sobre el territorio en disputa. Es oportuno en esta sección esbozar las siguientes actividades desarrolladas por Venezuela en la zona antes descrita, lo cual evidencia claramente el ejercicio de la soberanía de ese Estado.

a. Estudios y Proyectos Iníciales (1873-1947): A partir de 1873 se efectuaron diversos estudios y se presentaron distintas proposiciones y proyectos para la canalización de la Barra de Maracaibo, hasta una profundidad de $3,6^{\mathrm{m}}$ (12 pies). En 1894 el Estado Venezolano concedió permiso para tapar provisionalmente los caños Paijana y Oribor, como preliminares de un estudio práctico que se proponía hacer para la profundización de la barra, aunque tales trabajos nunca se ejecutaron. En 1914 se descubrió petróleo en escala comercial en Mene

\footnotetext{
${ }^{19}$ Constitución Nacional. Artículo 101. Los límites de Colombia son los establecidos en los Tratados Internacionales aprobados por el Congreso, debidamente ratificados por el Presidente de la República, y los definidos por los Laudos Arbítrales en que sea parte la Nación. Los límites señalados en la forma prevista por esta Constitución, solo podrán modificarse en virtud de Tratados aprobados por el Congreso debidamente ratificados por el Presidente de la República. Forman parte de Colombia, además del Territorio Continental, el Archipiélago de San Andrés Providencia y Santa Catalina, la Isla de Malpelo y demás Islas, Islotes, Cayos, Morros y Bancos que le pertenecen.

También son parte de Colombia, el Subsuelo, el Mar Territorial, la Zona Contigua, la Plataforma Continental, la Zona Económica Exclusiva, el Espacio Aéreo, el Segmento de la Órbita Geoestacionaria, el Espectro Electromagnético y el Espacio donde actúa, de conformidad con el Derecho Internacional o con las leyes Colombianas a falta de Normas Internacionales.

${ }^{20}$ Constitución de la República Bolivariana de Venezuela. Artículo 11: la Soberanía plena de la República se ejerce en los Espacios Continental e Insular, Lacustre y Fluvial, Mar Territorial, Áreas Marinas Interiores, Históricas y Vitales y las comprendidas dentro de las Líneas de Bases Recta que ha adoptado o adopte la República; el Suelo y Subsuelo de estos; el Espacio Aéreo Continental, Insular y Marítimo y los recursos que en ellos se encuentran, incluidos los genéticos, los de las especies migratorias, sus productos derivados y los componentes intangibles que por causas naturales allíse encuentren. El Espacio Insular de la República comprende el Archipiélago de los Monjes, Archipiélago de las Aves, Archipiélago de los Roques, Archipiélago de la Orchila, Isla la Tortuga, Isla la Blanquilla, Archipiélago los Hermanos, Islas de Margarita, Cubagua y Coche, Archipiélago de los Frailes, Isla la Losa, Archipiélago de los Testigos, Isla de Patos e Isla de Aves; y, además, Islas, Islotes, Cayos y Bancos situados o que emerjan dentro del Mar Territorial, en el que cubra la Plataforma Continental o dentro de los límites de la Zona Económica Exclusiva. Sobre los Espacios Acuáticos constituidos por la Zona Marítima Contigua, la Plataforma Continental y la Zona Económica Exclusiva, la República ejerce Derechos exclusivos de Soberanía y Jurisdicción en los términos, extensión y condiciones que determinen el Derecho Internacional Público y la Ley. Corresponden a la República Derechos en el Espacio Ultraterrestre Suprayacente y en las Áreas que son o pueden ser patrimonio de la comunidad, en los términos, extensión y condiciones que determinen los Acuerdos Internacionales y la Legislación Nacional.
} 
Grande y en 1925 se inicia el transporte de petróleo en gran escala con barcos pequeños. En enero de 1936, el Ministerio de Obras Públicas creó por decreto la comisión técnica para el estudio de la canalización de la barra. La comisión de estudios de la barra de Maracaibo inició sus labores con la información que le suministraron las compañías petroleras para la construcción de un canal de 30 pies de calado. En Febrero de 1938, el General C. W. Kutz, del cuerpo de Ingenieros del ejército de los Estados Unidos, cuyos servicios había contratado el gobierno de Venezuela a través de su embajada en Washington, presentó un informe de recomendaciones. En octubre de 1938 se Iniciaron los trabajos de dragado por el canal llamado Zaparita, utilizando un tanquero convertido en draga de tolvas. En 1947, el Cnel. Robinson, contratado nuevamente por el Gobierno Venezolano, preparó un Informe complementario al de 1940 proponiendo la construcción de un canal de 35 pies, el cual fue revisado por una comisión de expertos que dictaminó a favor del mismo, sugiriendo algunas modificaciones, en base a las cuales, el propio Cnel. Robinson preparó el informe definitivo de fecha 31 de julio de 1947, que sirvió de base para las primeras obras de canalización. Este canal quedaba naturalmente dividido en una parte interior de $22,5^{\mathrm{km}}$ de longitud y $183^{\mathrm{m}}$ ( 600 pies) de anchura y una parte exterior hacia el norte de la isla de Zapara de $12,5^{\mathrm{km}}$ de longitud y $305^{\mathrm{m}}$ (1.000 pies) de ancho. Este canal se había diseñado para el uso de tanqueros del tipo T-2, de 18.000 toneladas de peso muerto, capaces de cargar 114.000 barriles.

b. Construcción de Obras de Canalización (1952 - 1956): En 1952 se creó, por resolución del Ministerio de Minas e Hidrocarburos, una comisión ejecutiva de tres miembros, la cual tuvo a su cargo los trabajos iníciales de la apertura y construcción de la barra de Maracaibo. En junio del mismo año se creó, adscrito al Ministerio de Minas e Hidrocarburos, el Instituto Nacional de Canalizaciones con la finalidad de ocuparse, primordialmente, de la construcción del canal que comunica el lago de Maracaibo con el Golfo de Coquivacoa, obra de servicio público de vital importancia para ese país. La construcción del tramo interior se inició el 20 de abril de 1953 y la obra fue inaugurada el 7 de diciembre de 1953. Se extrajeron $30.650 .000^{(\mathrm{m} / 3}$ de material en 586 días. Los trabajos de dragado del tramo exterior se iniciaron el 28 de noviembre de 1954 y la obra se inauguró el 8 de diciembre de 1956. Esta fecha constituye la fecha oficial de terminación del período de construcción del canal con 35 pies de profundidad y el comienzo de la etapa de mantenimiento y mejoras del mismo.

c. Profundidades y Anchuras del Canal de Maracaibo (1957 - 1976): Después de inauguradas las obras, el Instituto Nacional de Canalizaciones comenzó a efectuar varias Mejoras. En Julio de 1976, el Ministerio de Minas e Hidrocarburos designó una comisión para que presentara un estudio sobre la política a seguir en cuanto a la profundidad a que debía mantener el canal de navegación de Maracaibo. Dicha comisión recomendó adoptar como profundidad mínima 42 pies referidos al nivel medio de las mareas mínimas mensuales, la cual se consideró adecuada para el tipo y número de tanqueros que transitaban por el canal.

d. Proyecto Maracaibo del Instituto Nacional de Canalizaciones (1962 - 1972): a partir de 1962 el Instituto Nacional de Canalizaciones y comenzó a desarrollar un programa formal de estudios hidráulicos y ecológicos. 
Lo anterior es una muestra clara de que la soberanía sobre el Golfo de Coquivacoa, ha sido detentada por el Estado Venezolano en todo su amplio territorio, hasta la parte por medio de la cual Colombia alega tener soberanía en los distintos Gobiernos de las diversas épocas del diferendo.

Es menester advertir que Colombia ha tenido presencia en el Golfo de Coquivacoa, y para esto es de gran utilidad citar a Germán Cavelier, que sobre el particular plantea que "en diversas oportunidades, Colombia ha realizado actos de presencia en el Golfo. Así se hizo con labores de pesca especialmente a partir del gobierno de Lleras Restrepo. Durante el gobierno de Pastrana Borrero ocurrió el Incidente entre buques de guerra que no tuvo consecuencias por el retiro del Buque Venezolano. El Ministro de Relaciones Exteriores, Augusto Ramírez Ocampo, acompañado de otros ministros y altas personalidades efectuó una navegación en el golfo, haciendo constar en la bitácora los puntos visitados sin obstáculos por parte de Venezuela pero posteriormente en ese país se reclamó a su Ministro de Relaciones Exteriores por no haber impedido ese viaje. Han existido, por otra parte, incidentes con buques de pesca y reclamaciones de los países. Pero luego del episodio de la Fragata ARC "Caldas" se cerró el Golfo para los buques Colombianos de toda clase.

\section{POLÍTICA EXTERIOR COLOMBIANA FRENTE AL DIFERENDO COLOMBO-VENEZOLANO}

En esta sección del presente trabajo, se analiza cómo ha sido la política exterior colombiana en el tratamiento del diferendo. La política exterior colombiana ${ }^{21}$ se encuentra direccionada en la Constitución Nacional a través de su Artículo 9 el cual consagra "(...) la política exterior de Colombia ${ }^{22}$ se orientará hacia la integración latinoamericana y del Caribe".

Es importante precisar que la política exterior de un estado contiene una serie de principios básicos que le dan sentido y que sirven de punto de mira para sus ejecutores. Sin embargo, debe distinguirse entre el discurso legitimador de la política exterior y los principios básicos que animan a la misma, para arribar a una adecuada comprensión de los hechos. Grosso modo podemos decir que la política exterior de Colombia se ha caracterizado por:

1) Un proceso gradual de desideologización y universalización de las relaciones internacionales. (Lemaitre, 1971)

2) La estrecha relación entre los procesos internos y la política exterior.

3) La utilización del derecho como instrumento privilegiado de política exterior.

\footnotetext{
${ }^{21}$ En el primer caso, las Relaciones se han desenvuelto tradicionalmente entre dos modelos, el del "Réspice Polum" y el del "Réspice Similia". De acuerdo con el primero, sería necesario Vincular estrechamente los Intereses Colombianos a los de los Estados Unidos, ganando con la amistad una cuota de favor. El segundo principio consiste en Mirar a los Semejantes como una Forma de Ganar Aliados, incrementando así eventualmente el poder negociador. (Lemaitre, 1971)

${ }^{22}$ Una buena Política en los últimos dos años ha conducido a un nuevo estado de las Relaciones con Venezuela, mediante una manera novedosa y eficaz de abordar los problemas comunes. Se ha innovado en Mecanismos de Cooperación Bilateral, y el diferendo con respecto a las Áreas Marinas y Submarinas en el Golfo de Venezuela ha dejado de ser el tema central y dominante de la Agenda entre los dos países. Además, ya pasaron los tiempos en que la Cancillería Colombiana era una Oficina de Fronteras y solo eso. Por ejemplo, la Evolución del Tratamiento de las Relaciones con Venezuela, ha llevado al Establecimiento de una Comisión Negociadora para la Delimitación de Áreas Marinas y Submarinas y para que se ocupe de cuatro temas adicionales: migraciones, cuencas hidrográficas, ríos internacionales y trabajos de demarcación y densificación de hitos fronterizos. (Ascanio, 1972)
} 
4) La importancia variable de la política económica.

5) La utilización de la diplomacia multilateral.

6) La limitación de los instrumentos de la política exterior.

Con lo hasta aquí expuesto, consideramos prudente advertir que la delimitación de áreas marinas y submarinas en el golfo de Coquivacoa, luego de tantos años de ser el eje central de la política exterior del Estado Colombiano, perdió su significación central ya que el auge del accionar Internacional cobro demasiada importancia, y sobre todo el tema de la seguridad colectiva, característica jerárquica del Derecho Internacional Público ${ }^{23}$.

Dentro de la nueva metodología adoptada cinco de los temas más controversiales delimitación de áreas marinas y submarinas, cuencas hidrográficas, ríos internacionales, demarcación y densificación de hitos, y migración pasaron a conocimientos de las comisiones negociadoras.

Este último asunto ha tenido importantes desarrollos, pues como señaló el entonces Canciller Venezolano, Miguel Ángel Burelli; la falta de ese límite nos ha llevado a incursionar muchas veces en el territorio del otro, sin voluntad pero por falta de una señal, por falta de unos mojones que hagan posible ese límite y eso es lo que estamos recomendando hacer.

La delimitación marítima y la conservación de cuencas constituyen las dos negociaciones macro sometidas a estudio por parte de una Comisión Negociadora Binacional durante los últimos diez años. Las comisiones se han reunido aproximadamente cuarenta veces desde su creación. En 1998 entregaron a los presidentes salientes y entrantes de Colombia, Ernesto Samper Pizano y Andrés Pastrana Arango, así como al presidente de Venezuela Rafael Caldera un informe de lo actuado hasta el momento.

El gobierno de Venezuela de Hugo Chávez Frías reiteró el interés por mantener el esquema bilateral yglobal de la negociación.

Todo el análisis anterior, nos muestra de manera clara que los gobiernos tanto de Colombia y de Venezuela, en desarrollo de su política exterior, encaminada a diversos temas los cuales dejan en un segundo plano las negociaciones en el diferendo Colombo-Venezolano; sobre este punto es válido decir que la política exterior de ambos siempre ha estado direccionada hacia el incumplimiento de las decisiones judiciales, inaplicabilidad de los tratados internacionales, inutilidad de los medios judiciales, que se muestran como política exterior indirecta en ambos Estados en conflicto; que se

\footnotetext{
${ }^{23}$ Sobre este punto es importante decir que en la Administración Betancourt, Colombia centro el énfasis de su accionar a nivel Internacional en la estrategia de Paz del Grupo de Contadora y el ingreso al Movimiento de los Países No Alineados. Por este motivo el tema del Diferendo Limítrofe Colombo-Venezolano en el Golfo de Coquivacoa quedó relegado a un segundo plano. Con el inicio de la administración Barco, en Colombia se especuló sobre la pronta solución del diferendo. Luego de varios intentos fallidos por reactivar el Dialogo Bilateral el gobierno de Colombia decidió acudir al Mecanismo del Tratado de 1939 para buscar la Conciliación. Venezuela por su parte se negó enfáticamente a acoger la Propuesta Colombiana.
} 
resume en ineficacia de los medios internacionales para resolver conflictos internacionales de manera directa por parte de los sujetos de derecho internacional y que los resultados de los medios de resolución de conflictos dependen exclusivamente de la voluntad de los estados.

En cuanto a la primera postura, esta es, a la que hace referencia a que en asuntos de gran importancia como lo son los asuntos internacionales en materia territorial y de límites, la voluntad unilateral estatal es capaz de frenar o entorpecer la solución de un conflicto, es por ello que a manera de recomendación ya como en algunos casos la Corte Internacional de Justicia en sus Fallos ha planteado que hay asuntos en donde la Jurisdicción Internacional debe ser obligatoria, independientemente de los asuntos previstos en el Artículo 36 de la Carta de Naciones Unidas, la cual concede al Consejo de Seguridad la facultad de recomendar los procedimientos o métodos de ajustes que sean apropiados para solucionar las controversias cuya continuación sean susceptibles de poner en peligro el mantenimiento de la paz y la seguridad internacional.

A su vez el Artículo 36, Parágrafo 3, se establece que al hacer tales recomendaciones el Consejo de Seguridad debe considerar que las Controversias de Orden Jurídico, por regla general, deben ser sometidas por las partes a la Corte Internacional de Justicia de conformidad con el Estatuto de la Corte.

Se evidencia que existe incumplimiento de las decisiones judiciales, dado que las decisiones adoptadas a través de los fallos arbítrales fueron inoperantes, ya que esas decisiones no sometieron las posiciones particulares de cada Estado, motivo por el cual se plantearon diversos argumentos que buscaban falsear la decisión adoptada.

\section{CONCLUSIONES}

Frente al problema jurídico planteado, esto es, como se desarrolló la política exterior de Colombia frente a la delimitación de fronteras marinas y submarinas en el Golfo de Coquivacoa, que en asuntos de alta trascendencia nacional e internacional como el diferendo Colombo Venezolano, es necesario por parte del Estado Colombiano que se fije una política exterior clara y definida que se encuentre conforme a la política internacional de los órganos y organismos internacionales que velen por el mantenimiento del orden público internacional ${ }^{24}$. En ese sentido, debemos señalar que en el caso colombiano la política exterior debe estar conforme a las disposiciones de la Constitución Nacional que al respecto plantea que las relaciones exteriores del Estado se fundamentan en la soberanía nacional, en el respeto a la autodeterminación de los pueblos y en el reconocimiento de los principios del derecho internacional aceptados por Colombia.

Es claro además que las negociaciones Colombo-Venezolanas en el diferendo en el Golfo de Coquivacoa deben redireccionarse y ajustar a la actualidad nuestra política exterior respetando los convenios pactados entre ambos estados, al igual que tratados multilaterales y los principios del Derecho Internacional.

${ }^{24}$ La doctrina de Derecho Internacional Público coincide con denominar a las normas de orden público internacional como normas de ius cojens inderogables por la voluntad de las parte, en este caso los estados cuando estas celebran un tratado, pues la importancia de tales normas radica en velar por la seguridad colectiva Vgr normas sobre el medio ambiente, derecho de la guerra, derechos humanos, DIH Etc. 
Para que las negociaciones puedan prosperar, a nuestro criterio, se hace necesario que las negociaciones Colombo-Venezolanas en el diferendo en el Golfo de Coquivacoa la política exterior de ambos Estados se a las reglas, tratados y convenios internacionales, pues tal política exterior debe respetar los convenios pactados entre ambos estados, al igual que tratados multilaterales (Monroy 2002) ${ }^{25}$.

\section{REFERENCIAS BIBLIOGRÁFICAS}

ASCANIO JIMENEZ, Agustín. (1972) “Venezuela y sus fronteras en la hora cero”. Caracas.

BECERRA RAMIREZ, Manuel. (2007) "Relación entre el Derecho Internacional y el Derecho Interno: el desafío de la aplicación de los Convenios de Ginebra”. III Encuentro de la Jurisdicción Constitucional.

CAVALIER, Germán. (1977) “Memoria Histórica Jurídica sobre el Asunto de los Monjes”. Bogotá.

COMANDANCIA GENERAL DE LA MARINA. (1967) "Derrotero de las Costas de Venezuela". Caracas: Ministerio de la Defensa, Comandancia General de la Marina, № MAN-HI-CGM-0002, mayo de 1967, pp. 83-105.

CODAZZI, Agustín. (1841) "Resumen de la Geografía de Venezuela" - Venezuela en Tomo I: Geografía Física. Tomo II: Geografía Política y Tomo III: Geografía de las Provincias. Caracas: Biblioteca Nacional de Cultura. Ministerio de Educación Nacional.

CORTE INTERNACIONAL DE JUSTICIA. «Caso relativo a la controversia sobre fronteras terrestres, insulares y marítimas (El Salvador contra Honduras: Intervención de Nicaragua)», que falló el 11 de septiembre de 1992.

CORTE CONSTITUCIONAL. Sentencia C-574 de octubre 28 de 1992; Sentencia C-400 de 1998.

DIEZ DE VELAZCO, Manuel. (1976) "Instituciones de Derecho Internacional Público". T. I. $3^{\circ}$ Ed. Madrid. Editorial Tecno.

GAVIRIA LIEVANO, Enrique. (2001) "Los Monjes en el Diferendo con Venezuela". Política Exterior Colombiana. Tomo II. Bogotá: Universidad Externado de Colombia.

GONZÁLES CAMPOS, Julio, et al., (1998) “Curso de Derecho Internacional Público”. 6 Ed. Madrid: Civitas.

GORI CABRERA, José Joaquín. (2006) “La Redención de los Monjes”. Derecho Internacional Contemporáneo, lo Público, lo Privado, los Derechos Humanos. Bogotá: 2006. Universidad del Rosario.

HOLGUÍN PELAEZ, Hernando. (1971) “Controversia de límites Colombia-Venezuela”. Eda, Bogotá.

LEMAITRE, Eduardo. (1971) “Panamá y su Separación de Colombia”. Bogotá: Biblioteca Banco Popular.

LONDOÑO PAREDES, Julio. (1975) "Cuestiones de límites de Colombia". Breviarios colombianos, 4, Bogotá, O.J.

${ }^{25}$ La costumbre es la forma primaria de manifestarse la comunidad ya que está formada por un conjunto de reglas observadas de hecho. Dichas reglas se revelan por la repetición de ciertos actos, acompañada del sentimiento de obligatoriedad. (Monroy 2002, p 87) 
LOZANO, Esther y MARULANDA, Pilar. (1982) “Cómo se hace la Política Exterior Colombiana”. Bogotá, Tercer Mundo.

MEDINA HIDALGO, Mariana. (2007) “La Corte Internacional de Justicia y Delimitación Marina”.

MONROY CABRA, Marco Gerardo. (1995) “Derecho de los Tratados”. $2^{\circ}$ Ed. Santa fe de Bogotá: Leyer.

MONROY CABRA, Marco Gerardo. (2002) “Derecho Internacional Público”. 5a ED. Bogotá: Temis.

MOYANO BONILLA, César y VÁSQUEZ ROCHA, Ernesto. (1971) “Los Monjes y las Bahías Históricas ante el Derecho Internacional". Bogotá: Temis.

PARDO, Rodrigo y TOKATLIAN, Juan. (1988) "Política Exterior Colombiana ¿De la Subordinación a la Autonomía?". Bogotá: Uniandes.

PEARSON, Frederick y ROCHESTER José Martín. (2001) “Relaciones Internacionales y Situación Global en el Siglo XXI". $4^{\circ}$ ED. Bogotá: Mc Gran Hill.

PEÑA, Margarita y MORA, Carlos Alberto. (1998) “Historia de Colombia. Introducción a la Historia Social y Económica". Bogotá: Norma, (Colección Nuestro Mundo y sus Hechos).

PERAZZO, Nicolás. (1982) “Historia de las Relaciones Diplomáticas entre Venezuela y Colombia”. 2a ED. Caracas: Imprenta Nacional.

PEREZ VILLA, Jorge. (2008) “Derecho Constitucional e Instituciones Políticas". Bogotá: Centro de Estudios Internacionales de Ciencia Jurídica y Filosofía del Derecho.

RALPH, Zacklin. (1975) “El Derecho del Mar en Evolución: La Contribución de los Países Americanos”. México: Fondo de Cultura Económica.

SILVA LUJAN, Gabriel. (1985) “Política Exterior ¿Continuidad o Ruptura?”. Reseña de un Debate. Bogotá: Cerec, 1985. (Serie Política Internacional No. 4 Centro de Estudios Internacionales UNIANDES).

RAMIREZ, Socorro y CADENAS, José María. (1999) “Colombia-Venezuela. Agenda Común para el Siglo XXI”. Bogotá: Tercer Mundo.

SOCORRO y RESTREPO, Luís Alberto. (1997) “Colombia entre la Inserción y el Aislamiento". Política Exterior Colombiana en los años Noventa. Bogotá: Universidad Nacional (Siglo del Hombre).

SORENSEN, Máx. (2004) "Manual de Derecho Internacional Público". 9a ED. México: Fondo de Cultura Económica.

TIRADO MEJIA, Álvaro. (2007) “El Estado y la Política en el Siglo XIX. Bogotá: Nomos.

TOKATLIAN, Juan G. (1988) "Teoría y Práctica de las Relaciones Internacionales: El Caso de Colombia", en Estudios Internacionales, Santiago de Chile.

TORRES DEL RíO, César. (1994) “Grandes Agresiones contra Colombia”. Bogotá: Roca.

VALOIS ARCE, Daniel. (1981) “Los Monjes ¿ Un Mito Trágico?”. Medellín: Ealon. 
VÁZQUEZ CARRIZOSA, Alfredo. (1976) “El Nuevo Derecho del Mar: Evolución y Proyecciones Económicas". Bogotá: Temis.

VÁZQUEZ CARRIZOSA, Alfredo. (1987) “Colombia y Venezuela: Una Historia Atormentada”. Bogotá, Tercer Mundo.

VILLA, Eduardo. (1985) “La Política Exterior de Colombia con relación al Golfo de Venezuela”, Caracas, Ed. Centauro.

WILLS OLAYA, Eduardo. (1992) "Problemas Fronterizos". ¿Tiene Colombia Políticas Definidas sobre Fronteras? ¿Las Conoce el Pueblo Colombiano? Cartagena: Bolívar.

ZALAMEA, Alberto. (1987) “Catálogo de Errores: La Crisis Colombo-Venezolana”. Bogotá, La Oveja Negra. 